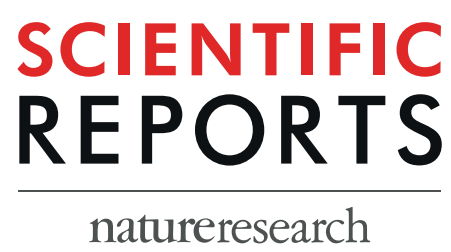

\title{
OPEN NAA at a high concentration promotes efficient plant regeneration via direct somatic embryogenesis and SE-mediated transformation system in Ranunculus sceleratus
}

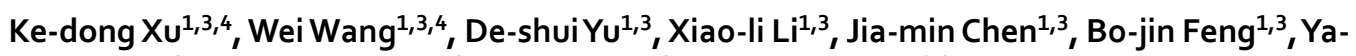
wen Zhao ${ }^{1,3}$, Meng-jia Cheng ${ }^{1,3}$, Xin-xin Liu ${ }^{1,3}$ \& Cheng-wei Li ${ }^{1,2,3^{*}}$

The novel methods for efficient plant regeneration via direct somatic embryogenesis (SE) and SEmediated transformation system under high concentration of NAA in Ranunculus sceleratus were established. On MS media containing a high concentration of NAA $(10.0 \mathrm{mg} / \mathrm{L})$ in the dark, all inoculated explants (root, stem and leaf) formed somatic embryos at high frequencies, respectively, 66.03, 126.47 and 213.63 embryoids per explant, and $100 \%$ of the embryoids developed into plantlets on $1 / 2 \mathrm{MS}$ rooting media. Morphological and histological analyses revealed that SE in $R$. sceleratus followed a classical pattern. All inoculated explants can be used as receptors for genetic transformation in $R$. sceleratus, through direct SE-mediated method after Agrobacterium infection. RcLEC1-B, as a marker gene, changed the number and morphology of flower organs and the development of cuticle in $R$. sceleratus, which indicated that the efficient transgenic system of $R$. sceleratus was established. To our knowledge, this is the first observation that both direct SE and transgenic transformation system, via induction of a single plant growth regulator, have been successfully constructed in $R$. sceleratus.
\end{abstract}

There are a variety of medicinal plants and ornamental flowers in Ranunculaceae family, especially the diploid plants, such as Aquilegia coerulea and Nigella damascene, which are ideal recipient system for the molecular mechanism research of flower development. Ranunculus sceleratus is a high rich source of valuable secondary metabolites, including alkaloids, tannins, flavonoids, isoscopoletin and protocatechuyl aldehyde ${ }^{1}$. It has been used as a traditional medicine in China for a long history ${ }^{2}$. R. sceleratus was always employed to prevent the replications of HBV (Hepatitis B virus) and HSV-1 (Herpes simplex virus type-1) ${ }^{1}$, and in the treatments of jaundice, rheumatic pains, asthma and urinary incontinence ${ }^{3} . R$. sceleratus is very effective as an insecticide against Drosophila melanogaster and Tribolium castaneum ${ }^{4}$. In addition, $R$. sceleratus has a high capacity for sewage disposal, it can absorb large amounts of nitrogen and phosphorus, accumulate and monitor the variation of heavy metals, such as $\mathrm{Cu}, \mathrm{Pb}, \mathrm{Fe}$ and $\mathrm{Zn}^{2,5}$, etc. However, until now, it has no a universal and stable genetic transformation method used in Ranunculaceae family, which greatly limits the research on the basic research and application research of Ranunculaceae plants.

In the process of plant somatic embryogenesis (SE), the induced somatic cells promote proliferation and dedifferentiation under an appropriate stimulus, for instance, plant growth regulators (PGRs), stress factors, spontaneous factors, etc., then initiate embryo development through redifferentiation ${ }^{6,7}$. Somatic embryogenesis structures can be used as recipient explant for genetic transformation systems ${ }^{8}$, which can generate transgenic plants with potential as industrial sources of useful compounds and thus act as plant bioreactors ${ }^{9}$; for example the hairy

\footnotetext{
${ }^{1}$ Key Laboratory of Plant Genetics and Molecular Breeding, Zhoukou Normal University, Zhoukou, 466001, China. ${ }^{2}$ College of Life Science and Technology, Henan Institute of Science and Technology, Xinxiang, 453003, China. ${ }^{3}$ Henan Key Laboratory of Crop Molecular Breeding and Bioreactor, Zhoukou Normal University, Zhoukou, 466001, China. ${ }^{4}$ These authors contributed equally: Kedong Xu and Wei Wang. *email: lichengweihist@163.com
} 


\begin{tabular}{|l|l|l|l|}
\hline \multirow{2}{*}{ NAA $(\mathbf{m g} / \mathbf{L})$} & \multicolumn{3}{|l|}{ Number of somatic embryos induced per explant } \\
\cline { 2 - 4 } & Root & Stem & Leaf \\
\hline 0 & $0.00 \pm 0.00 \mathrm{~kJ}$ & $0.00 \pm 0.00 \mathrm{~kJ}$ & $0.00 \pm 0.00 \mathrm{~kJ}$ \\
\hline 1.0 & $3.90 \pm 0.44 \mathrm{jkIJ}$ & $6.57 \pm 0.42 \mathrm{ijHI}$ & $9.33 \pm 0.49 \mathrm{iH}$ \\
\hline 2.5 & $14.80 \pm 0.44 \mathrm{hG}$ & $20.03 \pm 0.73 \mathrm{gF}$ & $19.37 \pm 0.74 \mathrm{gFG}$ \\
\hline 5.0 & $22.60 \pm 0.55 \mathrm{gEF}$ & $27.47 \pm 0.62 \mathrm{fE}$ & $35.17 \pm 0.68 \mathrm{eD}$ \\
\hline 10.0 & $66.03 \pm 0.80 \mathrm{cC}$ & $126.47 \pm 2.23 \mathrm{bB}$ & $213.63 \pm 4.76 \mathrm{aA}$ \\
\hline 20.0 & $27.33 \pm 0.85 \mathrm{fE}$ & $35.13 \pm 0.60 \mathrm{eD}$ & $39.23 \pm 0.50 \mathrm{dD}$ \\
\hline
\end{tabular}

Table 1. Effect of NAA at different concentrations on induction of somatic embryos from root, stem and leaf explants of $R$. sceleratus. The mean and standard error per treatment were calculated from 300 explants on 30 petri dishes (treated as 30 replicates). Capital and lowercase letters indicate a significant difference at the $1 \%$ and 5\% probability level respectively. Significant differences were analyzed with a Duncan test using SPSS 16.0.
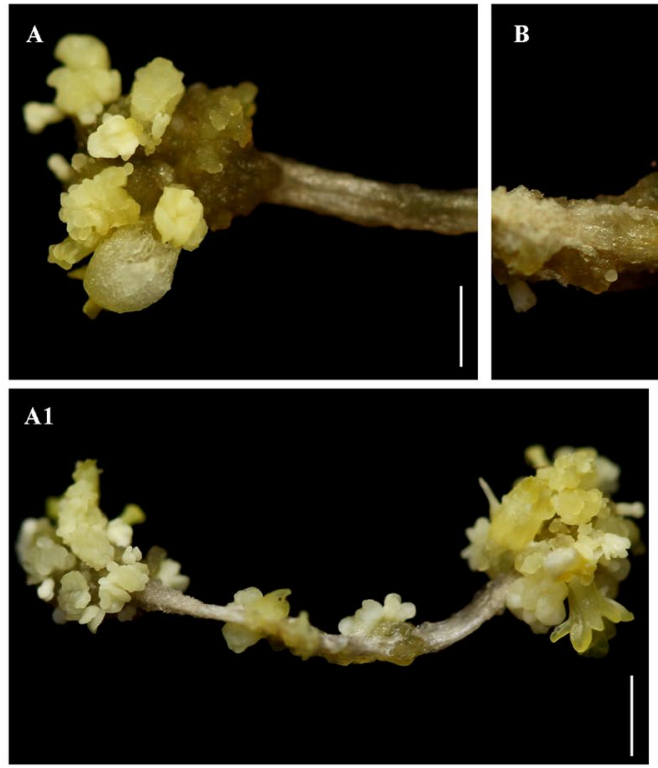

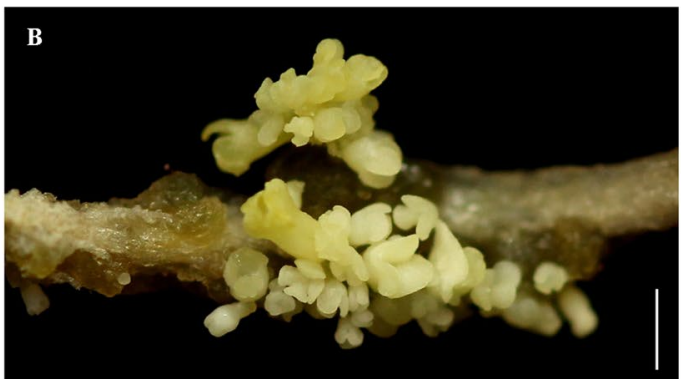

B1

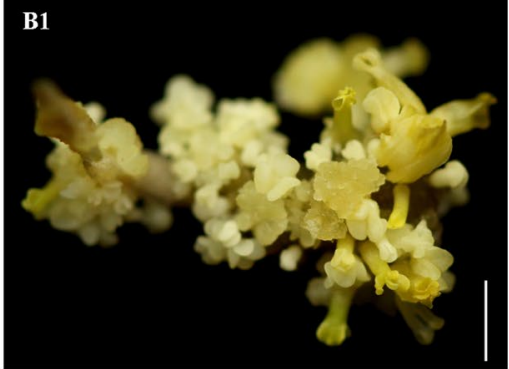

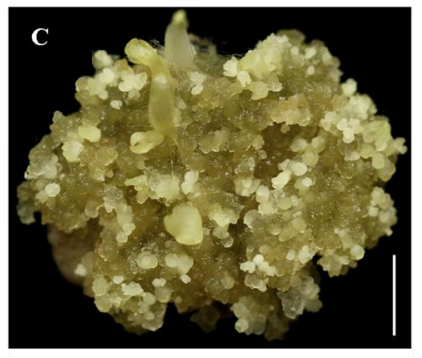

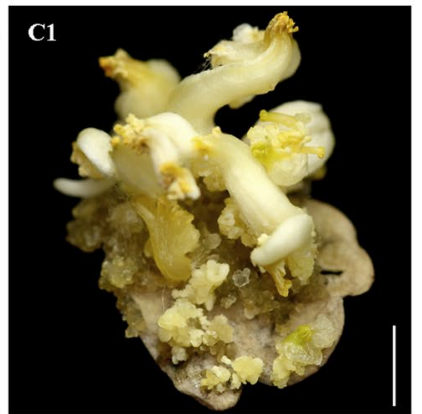

Figure 1. Induction of somatic embryogenesis from root, stem and leaf explants of R. sceleratus. (A-C) Early developmental stages; (A1-C1) Late developmental stage; (A,A1) Root explants; (B,B1) Stem explants; (C,C1) Leaf explants. Bars $(\mathbf{A}, \mathbf{C}, \mathbf{A} 1, \mathbf{B} 1, \mathbf{C 1})=0.5 \mathrm{~cm} ; \operatorname{Bar}(\mathbf{B})=0.25 \mathrm{~cm}$.

roots of Silene vulgaris ${ }^{10}$ and secondary metabolite production ${ }^{11}$. However, until now, the efficient regeneration and transgenic system of Ranunculaceae family has not been established; there has been no report of direct SE induction of $R$. sceleratus, although previous landmark studies have been done on Ranunculus sp., such as $R$. asiaticus $^{12,13}$. Here, we present a regeneration system via direct SE and SE-mediated transgenic system of $R$. sceleratus, which will contribute to the variety improvement, the construction of SE based bioreactor, and the basic theoretical research of Ranunculaceae plants as a reference system.

\section{Materials and Methods}

Plant materials and explant preparation. Seeds of R. sceleratus were generously provided by Prof. Le Zhao (College of Pharmacy, Henan University of Chinese Medicine, Henan, China), which were sterilized with $75 \%(\mathrm{v} / \mathrm{v})$ ethanol for $0.5-1 \mathrm{~min}$, rinsed 3-5 times with sterilized distilled water, then soaked in $2.5 \%(\mathrm{v} / \mathrm{v})$ sodium hypochlorite for 9-10 min and rinsed 3-5 times with sterilized distilled water. The sterilized seeds were placed on MS medium supplemented with $30 \mathrm{mg} / \mathrm{L}$ sucrose and $8.0 \mathrm{~g} / \mathrm{L}$ agar $(\mathrm{pH} 6.06)$ to obtain sterile seedlings; an average of 15 to 20 seeds per bottle was used. The germinating seeds were cultivated at $25^{\circ} \mathrm{C}$ with a $16 \mathrm{~h} \mathrm{light} / 8 \mathrm{~h}$ dark photoperiod (150-180 $\mu \mathrm{mol} \cdot \mathrm{m}^{-2} \mathrm{~s}^{-1}$ ). After two weeks of cultivation, the seedling height is about $4-5 \mathrm{~cm}$ and developed into plantlets with roots, which is the optimal state for induction of SE.

Induction of SE. Leaf discs about $1-1.5 \mathrm{~cm}^{2}$ in area, and root and stem segments about $1-2 \mathrm{~cm}$ long (without axillary buds on stem segments) were excised from $R$. sceleratus plantlets for use as explants for the induction of somatic embryogenesis. The explants were put on MS media with $30 \mathrm{~g} / \mathrm{L}$ sucrose and $3.6 \mathrm{~g} / \mathrm{L}$ gellan gum (pH 5.8) supplemented with 1-naphthaleneacetic acid (NAA) at concentrations of 1.0, 2.5, 5.0, 10.0 and $20.0 \mathrm{mg} / \mathrm{L}$. The inoculated explants were cultivated at $25 \pm 1{ }^{\circ} \mathrm{C}$ in the dark or under low light $\left(60 \mu \mathrm{mol} \cdot \mathrm{m}^{-2} \mathrm{~s}^{-1}\right)$ conditions to induce SE. The process of SE development was recorded using a digital camera (EOS 600D, Canon Inc., Japan) 

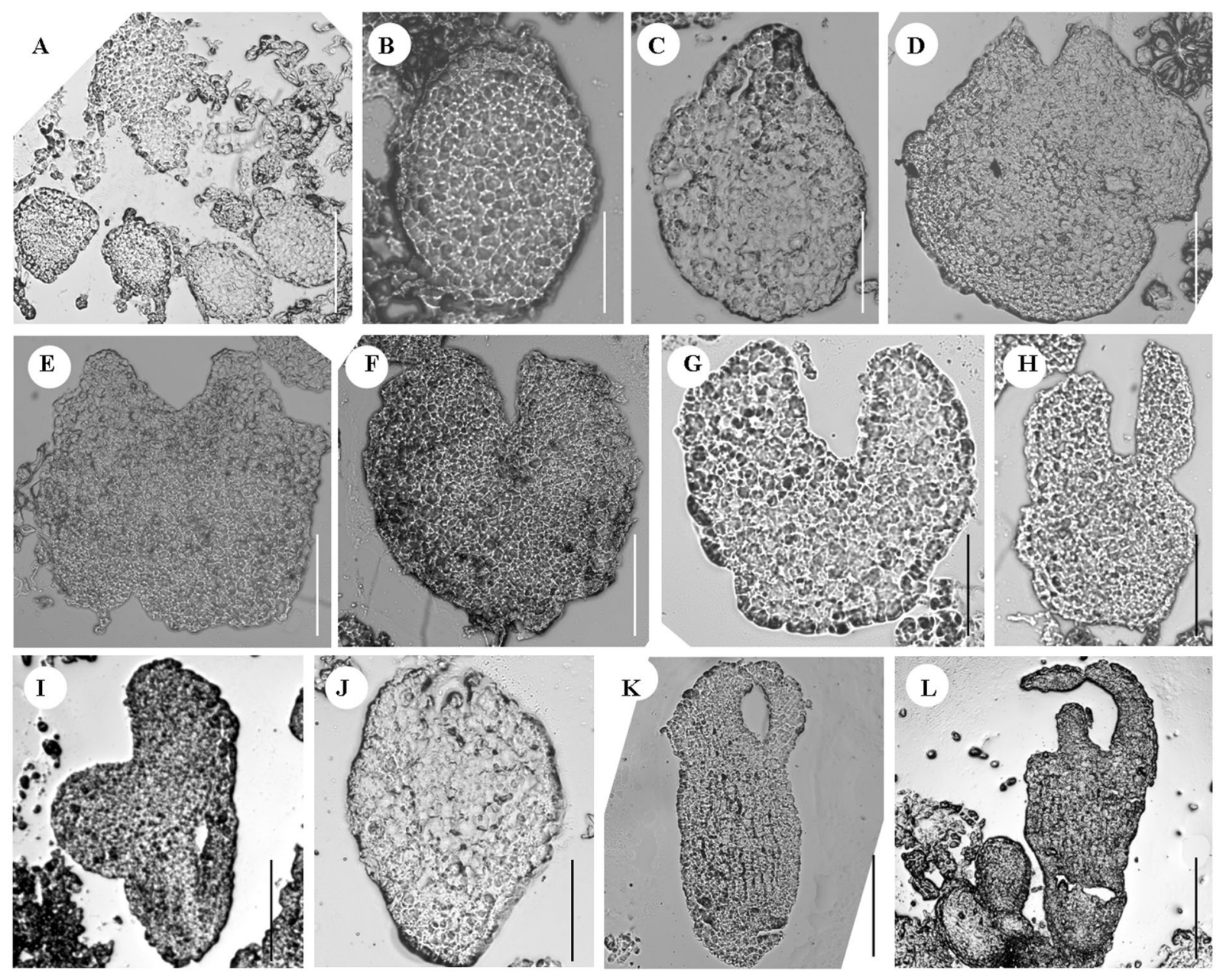

Figure 2. Microscopic images of different developmental stages of somatic embryogenesis in R. sceleratus, obtained using frozen section technique. (A) Multiple embryoids induced from leaf explant; (B) Globular embryo; (C) Transitional globular-heart embryo; (D-G) Heart embryos; (H) Torpedo-shaped embryo; (I-L) Cotyledon embryos. Bar $(\mathbf{A})=100 \mu \mathrm{m} ; \operatorname{Bars}(\mathbf{B}, \mathbf{C})=50 \mu \mathrm{m}$; Bars $(\mathbf{D}-\mathbf{G})=75 \mu \mathrm{m} ; \operatorname{Bar}(\mathbf{H})=200 \mu \mathrm{m}$; Bars $(\mathbf{I}, \mathbf{J})=200 \mu \mathrm{m} ; \operatorname{Bars}(\mathbf{K}, \mathbf{I})=400 \mu \mathrm{m}$.

and a stereomicroscope (SMZ800, Nikon Corporation, Japan). To evaluate the frequency of SE from explants, thirty replicates of each of 10 explants were used.

Histological analyses of SE. Frozen sections of somatic embryos at different developmental stages were prepared for microscopy according to a previously published method ${ }^{13}$, and imaged using an optical microscope (BX 41, Olympus Corporation, Japan).

Plantlet formation from somatic embryos. Without no change in the media, the PGR supplement and the dark conditions, somatic embryos spontaneously developed into plantlets. When plantlets had reached a length of $1-2 \mathrm{~cm}$ they were separated and transferred to rooting medium $(1 / 2 \mathrm{MS}$ salt $+1 / 2 \mathrm{~B} 5$ vitamins $+10 \mathrm{~g} / \mathrm{L}$ sucrose $+8.0 \mathrm{~g} / \mathrm{L}$ agar, $\mathrm{pH} 5.8$ ) to induce root formation. To evaluate the frequency of regeneration of plantlets from somatic embryos, thirty replicates of each of 10 somatic embryos were set.

Isolation and overexpression vector construction of RcLEC1-B. The RNA isolation, DNase treatment, reverse transcription and isolation of RcLEC1-B (LEAFY COTYLEDON1-B) were made according to the published method ${ }^{14}$. The nucleotide sequence was submitted to GenBank, was deposited in GenBank under accession number KM115581.1. The RcLEC1-B ORF was cloned into the KpnI and BamHI sites of pCAMBIA2300 to produce the overexpression vector pCAMBIA2300-RcLEC1-B. This vector was introduced into Agrobacterium tumefaciens (GV3101) by means of freeze-thawing ${ }^{14}$. In addition, the binary expression vector pBI121 carrying GUS reporter gene was used to analysis of transgenic efficiency via GUS histochemical assay.

Plant transformation via direct SE. The root, stem and leaf explants were immersed in Agrobacterium suspension (1/2 MS salt $+1 / 2$ B5 vitamins $+50 \mathrm{~g} / \mathrm{L}$ sucrose, $\mathrm{pH} 5.8)$ and uniformly shocked in the dark for 8-10 min. The explants were dried with sterile tissue paper and transferred to co-culture medium (MS 

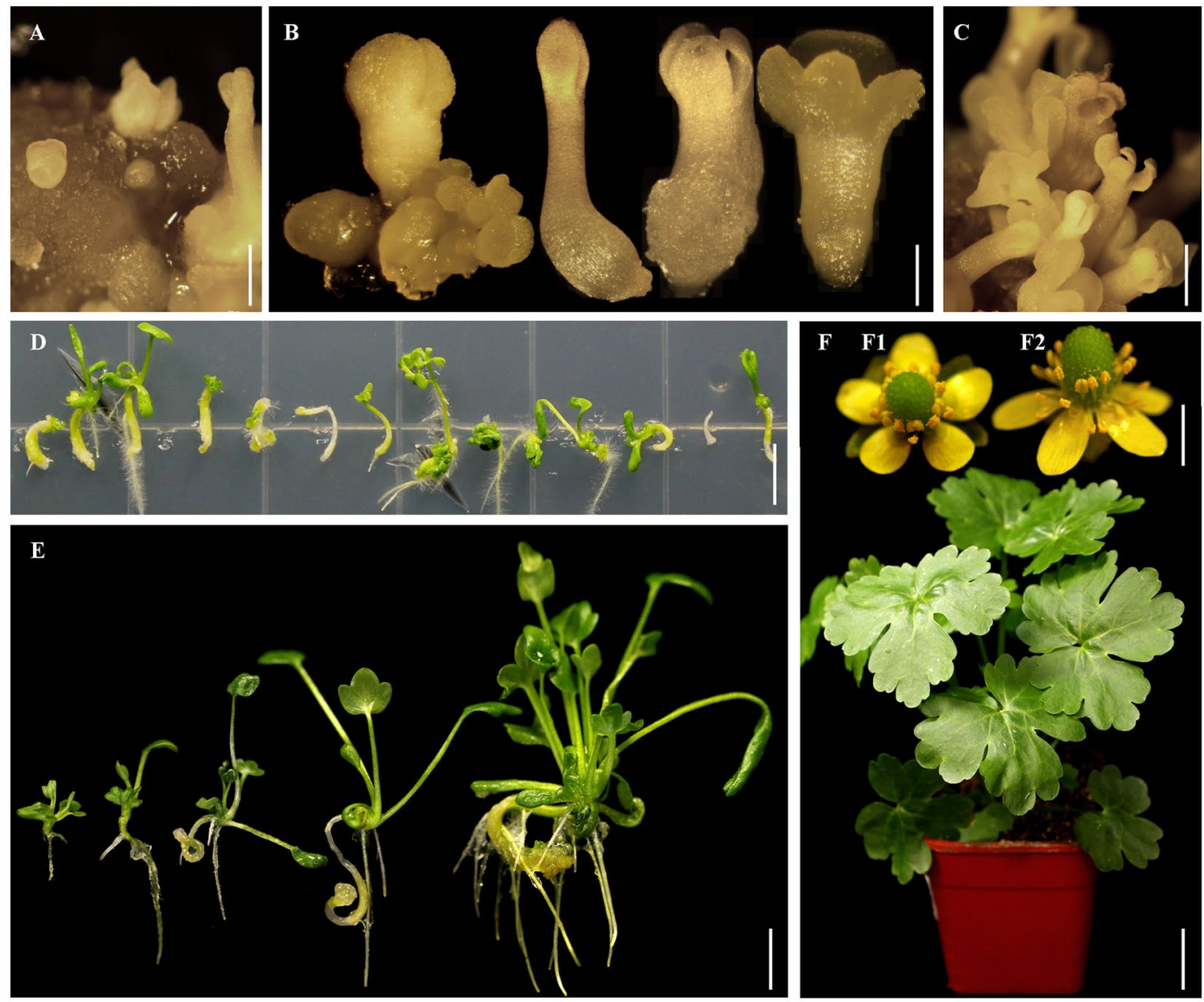

Figure 3. The process of regeneration of R. sceleratus via SE. (A) Multiple embryoids at different developmental stages induced on leaf explant; (B) The embryoid developmental process, showing many kinds of cotyledon embryos with different numbers of cotyledons; (C) Mature embryoids; (D) The induction of roots from embryoids; (E) Regenerated plantlets; (F) A regenerated plant; $($ F1,F2) The flowers of regenerated plant. Bar $(\mathbf{A})=200 \mu \mathrm{m} ; \operatorname{Bar}(\mathbf{B})=300 \mu \mathrm{m} ; \operatorname{Bar}(\mathbf{C})=400 \mu \mathrm{m} ; \operatorname{Bar}(\mathbf{D})=0.5 \mathrm{~cm} ; \operatorname{Bar}(\mathbf{E})=1 \mathrm{~cm} ; \operatorname{Bar}(\mathbf{F})=2 \mathrm{~cm} ; \operatorname{Bars}$ $(\mathbf{F} 1, \mathbf{F} 2)=0.35 \mathrm{~cm}$

salt $+\mathrm{B} 5$ vitamins $+40 \mathrm{mg} / \mathrm{L}$ acetosyringone $(\mathrm{AS})+30 \mathrm{~g} / \mathrm{L}$ sucrose $+8.0 \mathrm{~g} / \mathrm{L}$ agar, $\mathrm{pH}$ 5.8) and kept in the dark for $72 \mathrm{~h}$. Then the explants were placed on the selective culture medium, with composition MS salt $+\mathrm{B} 5$ vitamins $+10 \mathrm{mg} / \mathrm{L} \mathrm{NAA}+100 \mathrm{mg} / \mathrm{L} \mathrm{Kan}+500 \mathrm{mg} / \mathrm{L} \mathrm{Carb}+30 \mathrm{~g} / \mathrm{L}$ sucrose $+3.6 \mathrm{~g} / \mathrm{L}$ gellan gum $(\mathrm{pH} 5.8)$. Formed embryoids on explants were isolated and transferred to rooting medium.

GUS histochemical assay on somatic embryos. GUS histochemical assay was performed with Kan-resistant positive embryoids according to Jefferson's protoco ${ }^{15}$ with some modification. The embryoids were stained with $0.96 \mathrm{mM} 5$-bromo-4-chloro-3-indolyl $\beta$-D-glucuronide (X-Gluc) (dissolved by N, $\mathrm{N}$-dimethylformamide) in PBS (0.1 M, pH 7.0) containing $0.5 \mathrm{mM}$ EDTA, $5 \mathrm{mM}$ potassium ferricyanide, $5 \mathrm{mM}$ potassium ferrocyanide, $2 \%$ carbinol and $0.1 \%(\mathrm{v} / \mathrm{v})$ Triton X-100, overnight under $37^{\circ} \mathrm{C}$. The chlorophyll was removed by using $100 \%$ ethanol after X-Gluc staining. Then samples were rehydrated in ethanol series $75,37.5$ and $18.75 \%$ ethanol ( $15 \mathrm{~min}$ each step), placed in $5 \%$ ethanol and $25 \%$ glycerol for $30 \mathrm{~min}$, preserved in $50 \%$ glycerol for further observation and photograph.

Statistical analysis. Using SPSS 16.0 software, analyses of variance (ANOVA) with $99 \%$ and $95 \%$ confidence intervals were applied to the digital data.

\section{Results}

Induction of SE from root, stem and leaf explants on media with NAA in the dark. To establish the SE induction system, NAA at concentrations of 1.0, 2.5, 5.0, 10.0 and $20.0 \mathrm{mg} / \mathrm{L}$ was tested in order to optimize PGR conditions, and different types of explants from root, stem and leaf material were investigated. The results showed that with all the investigated supplementary concentrations of NAA in the media, SE was successfully induced from all of the explant types tested, though at different induction frequencies. However, no SE induction was observed from root, stem or leaf explants on media without NAA (Table 1). Of the concentrations tested, $1.0 \mathrm{mg} / \mathrm{L}$ NAA resulted in the smallest average numbers of induced somatic embryos (9.33 from leaf, 6.57 from stem and 3.90 from root) and only a small amount of rhizoids ${ }^{16}$ per explant (Table 1 ). However, a concentration of 

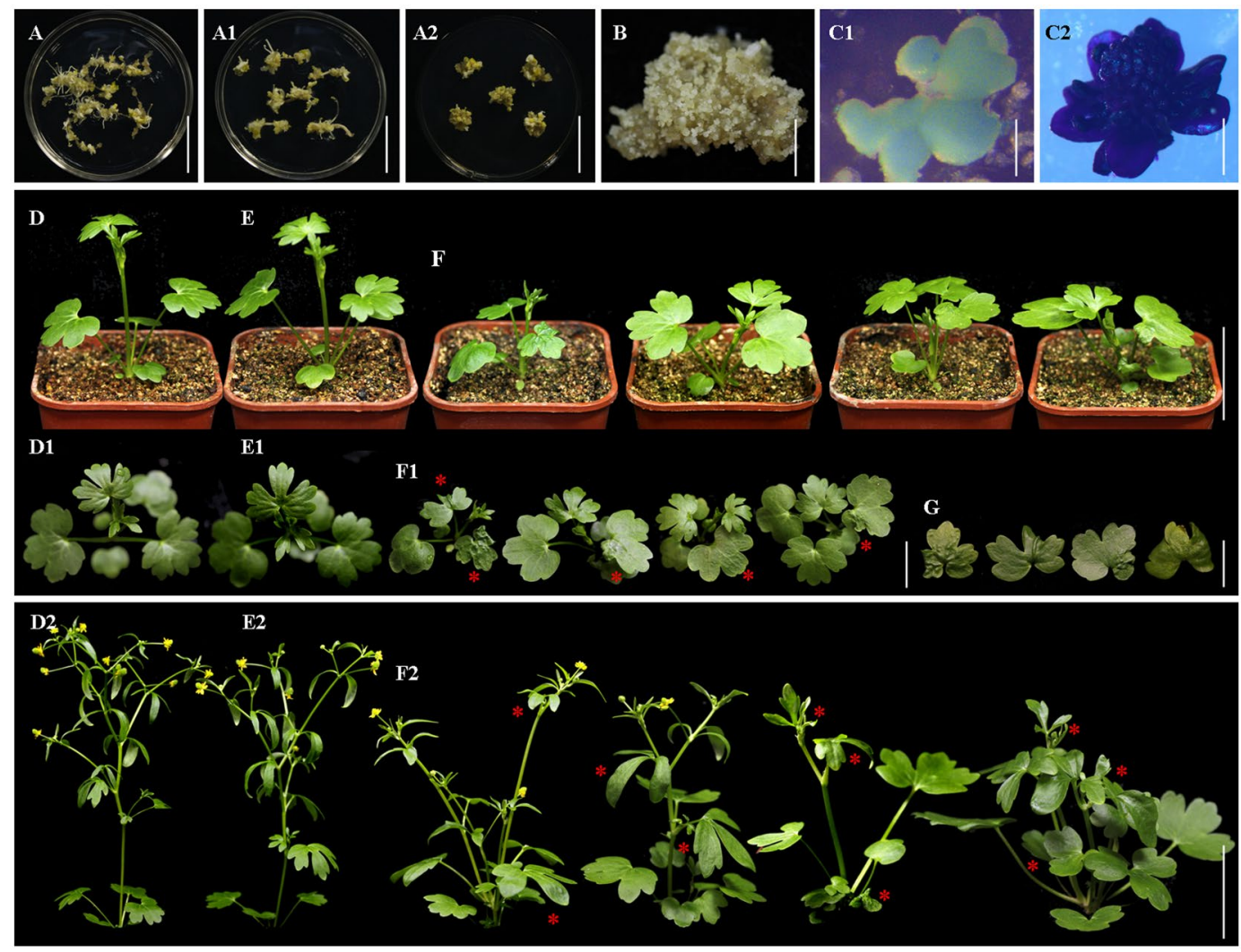

Figure 4. Overexpression of RcLEC1-B results in dwarfing and abnormal flower organs in R. sceleratus. $(\mathbf{A}, \mathbf{A 1}, \mathbf{A 2}, \mathbf{B})$ The transformation process of $R$. sceleratus. Multiple kan-resistant positive embryoids at different developmental stages induced on root, stem and leaf explants; (A) Root explant; (A1) Stem explant; (A2,B) Leaf explants; (C1) GUS assay on positive embryoids; (C2) GUS assay on positive flower; (D,D1) Wild-type plants (15 d); (E,E1) Empty vector (pCAMBIA2300) plant (15 d); (D2) Wild-type plant (30 d); (E2) Empty vector plant (30 d); (F,F1) RcLEC1-B-OE R. sceleratus with dwarfing plant-type (15 d); (F2) RcLEC1-B-OE plants (30 d); (G) The cuticle defects on leaves of RcLEC1-B-OE R. sceleratus. $\operatorname{Bar}(\mathbf{A}, \mathbf{A 1}, \mathbf{A 2})=3 \mathrm{~cm} ; \operatorname{Bar}(\mathbf{B})=1 \mathrm{~cm} ; \operatorname{Bar}$ $(\mathbf{C 1})=500 \mu \mathrm{m} ; \operatorname{Bar}(\mathbf{C 2})=5 \mathrm{~mm}$; Bars $(\mathbf{D}, \mathbf{D} 2, \mathbf{E}, \mathbf{E} 2, \mathbf{F}, \mathbf{F 2})=3.5 \mathrm{~cm} ; \operatorname{Bars}(\mathbf{D 1}, \mathbf{E 1}, \mathbf{F 1})=1 \mathrm{~cm} ; \operatorname{Bar}(\mathbf{G})=1 \mathrm{~cm}$.

$2.5 \mathrm{mg} / \mathrm{L}$ NAA also resulted in a relatively small amount of SE and produced a few frog egg-like bodies (FELBs) ${ }^{17}$ per explant (Table 1). A concentration of $10.0 \mathrm{mg} / \mathrm{L}$ NAA resulted in the highest average numbers of somatic embryos (66.03 from leaf, 126.47 from stem and 213.63 from root) induced per explant (Table 1). These results showed that for R. sceleratus leaf explants are the best type to use (Fig. 1), and that $10.0 \mathrm{mg} / \mathrm{L}$ NAA is the optimal PGR concentration. We also tested the effect of light; this experiment showed that under light conditions no SE was induced from any of the types of explant tested on media containing any of the above-mentioned concentrations of NAA, suggesting that incubation under dark conditions is necessary for SE induction in R. sceleratus. We found that the embryoids induced exhibited the five classic developmental stages in terms of morphological structure: multicellular pro-embryo, globular embryo, heart-shaped embryo, torpedo-shaped embryo, and cotyledon embryo (Fig. 2). However, there were many kinds of cotyledon embryos with different numbers of cotyledons, with two, three, four and multiple cotyledons all being observed in cotyledon embryos (Fig. 1A,B,A1,B1).

Frozen sectioning revealed the development process of somatic embryos. A frozen sectioning technique was employed to analyze the developmental process during SE. As SE progressed, globular embryo (Fig. 2B), heart-torpedo embryo (Fig. 2D-G), torpedo-shaped embryo (Fig. 2H), and cotyledon embryo (Fig. 2I-L) were formed.

Plantlet formation from somatic embryos in vivo and GUS histochemical assay. Plantlets could be induced in vivo from $R$. sceleratus somatic embryos. Somatic embryos produced in vivo on the induction medium was able to spontaneously develop into plantlets; each somatic embryo structure generally developed only one plantlet (Fig. 3B,D,E). The formed somatic embryos were stained in blue after GUS-staining (Fig. 4C1).

Overexpression of RCLEC1-B results in dwarfing and abnormal flower organs. Overexpression of RcLEC1-B in R. sceleratus resulted in slightly dwarfed plants with folded leaves (Fig. 4F,F1,F2,G) for the defective cuticle. The abnormal androecium and gynoecium were observed in RcLEC1-B-OE R. sceleratus. RcLEC1-B-OE affected the variable numbers in floral organs per flower in $R$. sceleratus with $0-5$ sepals, $2-14$ petals and 0-16 stamens; especially, the transition state petals with obvious notch appearance in RcLEC1-B R. sceleratus 

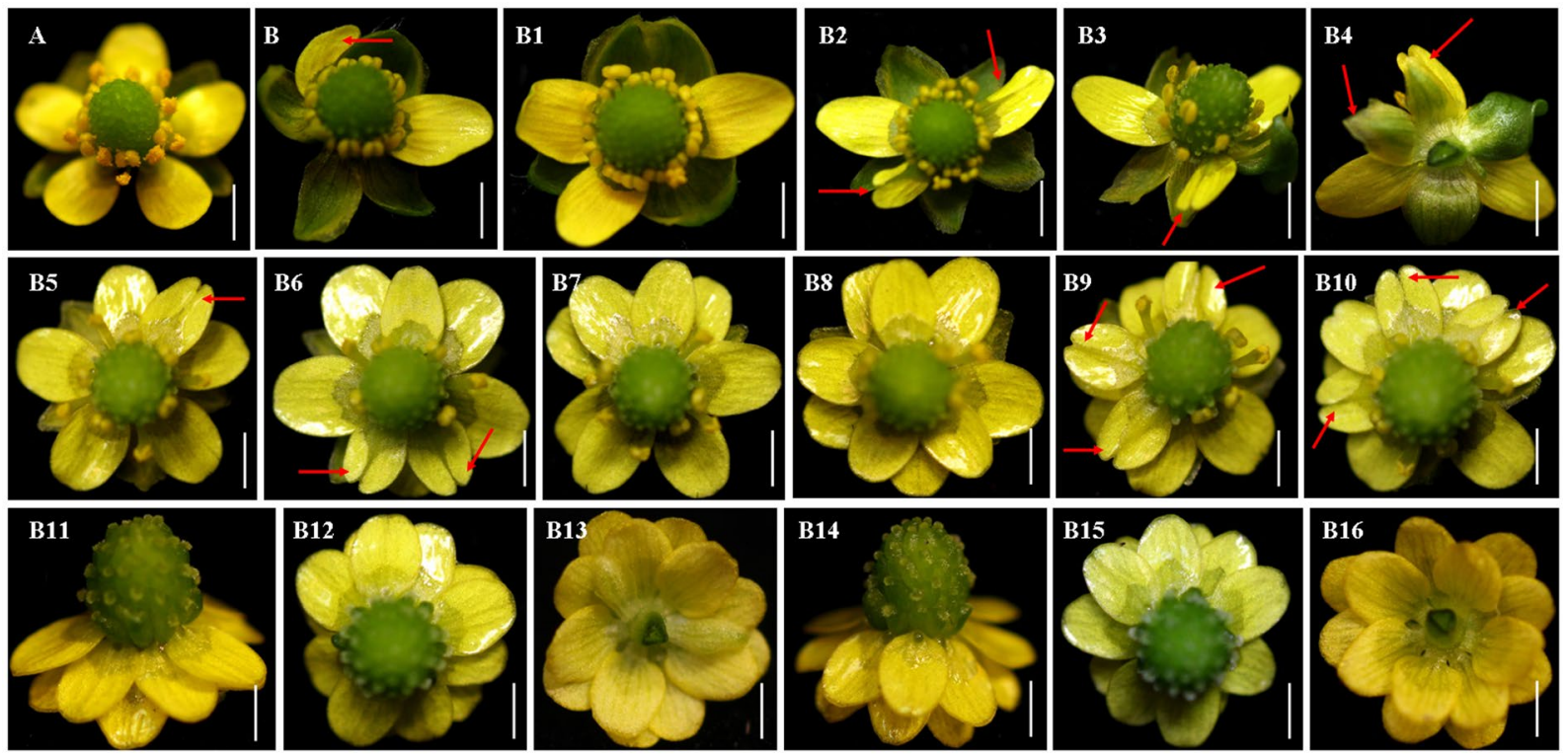

Figure 5. Morphology and numbers of floral organs of wild-type plant and RcLEC1-B-OE R. sceleratus. (A) Wild-type plant with five sepals, five petals, sixteen stamens (always more than ten) and one aggregate pistil (always including almost 100 achenes); (B-B16) RcLEC1-B-OE flowers; (B-B10) RcLEC1-B-OE flowers contained unnormal transition petal structures; (B4) Indistinguishable structures intermediate between sepals and petals; (B11-B16) No sepal and stamen. The red arrows mark the developmental malformed petals. Bars

$(\mathbf{A}, \mathbf{B}-\mathbf{B} 16)=2 \mathrm{~mm}$.

(Fig. 5B,B2-B6,B9,B10). In the statistics of the efficiency of genetic transformation, we found that the highest transformation efficiency was approximately $70 \%$, was obtained in leaf explant; that of the stem explant was $40 \%$, and the minimum transformation efficiency was only $20 \%$ in root explant.

\section{Discussion}

Somatic embryogenesis is model system for reveal the developmental mechanism of plant zygotic embryo and a valuable tool for plant regeneration ${ }^{6,18}$. The results of previous studies showed that various treatments could be successfully applied to the induction of SE in higher plants; these conditions include PGRs, such as $2,4-\mathrm{D}^{17,19}$, $\mathrm{NAA}^{16}$, TDZ ${ }^{16,19}$, and IAA ${ }^{20}$; desiccation ${ }^{20}$; osmotic stress ${ }^{21}$; polyamines $^{22}$, sugars $^{23-26}$, salts ${ }^{27}$, and metal ions ${ }^{28}$. Always, the PGRs with suitable concentration, variety and combination are very important to SE and plant propagation $^{29}$. In our study, it showed that the induced effect of SE under high concentration NAA $(10.0 \mathrm{mg} / \mathrm{L})$ is optimal, however, it needs to be strictly dark. The induction of SE in $R$. sceleratus under light was failure, which was consistent with the results of FELB in Solanum nigrum ${ }^{17}$. On the contrary, the induction of PLB structure in Rosa canina need involve high light condition ${ }^{19}$, and in Trichosanthes kirilowii the second stage of induction of rhizoid tubers (RTB), after rhizoid induction, also required light ${ }^{16}$. Optimization of light conditions is therefore important for the induction of different somatic embryo structures in different plant species. In this study, we found that the optimum concentration of NAA on induction of SE in $R$. sceleratus was $10.0 \mathrm{mg} / \mathrm{L}$, which was much higher than that $(1.0 \mathrm{mg} / \mathrm{L})$ on induction of RTB in T. kirilowii ${ }^{16}$. The same PGR with different concentrations always can successfully induce different SE structures, which indicates that the concentration of PGR plays a key role in plant SE activation, however, the specific mechanism is still unclear. In this study, all types of explants have the potential to successfully induce SE, nevertheless, the induction results indicated that the leaf was the best explant with a higher frequency on SE induction compared with stem and root explants.

We conclude that the SE induction of $R$. sceleratus in this report, possess some traits based on the following reasons. In summary: (1) To our knowledge, this is first report of a method for the direct induction of SE in R. sceleratus; (2) There are five classic stages in the development of somatic embryo structures: pro-embryo, heart-shaped embryo, globular embryo, torpedo-shaped embryo and cotyledon embryo (Fig. 2). (3) We observed many kinds of cotyledon embryos with cotyledon numbers ranging from two to four, and also multiple cotyledons on polymeric cotyledon embryos (Figs. 1 and 3); (4) The results showed that SE often form individually on the surface of explants; (5) Darkness is necessary for induction; (6) The regeneration system via SE has a high regeneration efficiency (66.03-213.63 plantlets per explant), and it is therefore reasonable to predict that $R$. sceleratus transformation based on this regeneration system might also be high-efficiency. Further study is needed to determine whether the induction pathway developed here for $R$. sceleratus can be established in other species of Ranunculaceae.

The transcription factor $L E C 1-B^{14}$, one of the CCAAT box-binding factors (CBFs) known as the HAP3 (HEME-ACTIVATED PROTEIN3) group, was isolated in protocorm-like body (PLB) ${ }^{19}$, a special SE structure of Rosa canina. It was proved in our previous studies that RcLEC1-B-OE significantly changed the number and morphology of floral organs, formed the transition state structures and regulated the development of cuticle in 
Arabidopsis ${ }^{14}$. In this study, the same results were obtained in RcLEC1-B-OE R. sceleratus, which changed in the numbers of reproductive organs, absence of floral organs, especially, the transition state structures between petal and sepal. The above results confirmed that the same function of RcLEC1-B gene was verified in R. sceleratus, and the genetic transformation system of $R$. sceleratus via SE has been successfully constructed, together with the overexpression results of reporter gene (GUS). To our knowledge, this is the first observation of transgenic system via direct SE-mediated method, have been successfully constructed in Ranunculaceae plant. Our findings will greatly promote the researches on metabolic mechanism of secondary metabolites, molecular mechanism of heavy metals accumulation and tolerance, molecular breeding and basic research of the rare flowers of Ranunculaceae family, such as R. japonicus, R. asiaticus, Aquilegia coerulea and Nigella damascene, etc.

\section{Conclusion}

Here, we applied SE approach to established efficient plant regeneration and transformation system in $R$. sceleratus. The high concentration of NAA $(10.0 \mathrm{mg} / \mathrm{L})$ is a crucial regulatory factor for the SE initiation of $R$. sceleratus. Leaf is the optimal explant formed somatic embryos at high frequencies, comparing with root and stem. All the three kinds of inoculated explants can be used as recipient materials for genetic transformation, in spite of the efficiencies of both regeneration via SE and transformation of leaf are higher. The SE of $R$. sceleratus followed a classical pattern indicated by morphological and histological analyses. The uniform results of RcLEC1-B overexpression in either $R$. sceleratus or Arabidopsis, together with GUS staining result, showed that both direct SE and transgenic transformation systems have been successfully constructed in R. sceleratus.

Received: 23 May 2019; Accepted: 15 November 2019;

Published online: 04 December 2019

\section{References}

1. Li, H. et al. Evaluation of antiviral activity of compounds isolated from Ranunculus sieboldii and Ranunculus sceleratus. Planta Med. 71, 1128-1133(2005).

2. Mei, H., Zuo, S., Ye, L., Wang, J. \& Ma, S. Review of the application of the traditional Chinese medicinal herb, Ranunculus sceleratus Linn. J Med Plants Res. 6, 1821-1826 (2012).

3. Umair, M., Altaf, M. \& Abbasi, A. M. An ethnobotanical survey of indigenous medicinal plants in Hafizabad district, PunjabPakistan. PLoS One. 12, e0177912 (2017).

4. Bhattacharyya, P. R., Nath, S. C. \& Bordoloi, D. N. Insecticidal activity of Ranunculus sceleratus (L.) against Drosophila melanogaster and Tribolium castaneum. Indian J Exp Biol. 31, 85-86 (1993).

5. Farahat, E. A. \& Galal, T. M. Trace metal accumulation by Ranunculus sceleratus: implications for phytostabilization. Environ Sci Pollut R. 25, 4214-4222 (2018).

6. Luo, Y. \& Koop, H. U. Somatic embryogenesis in cultured immature zygotic embryos and leaf protoplasts of Arabidopsis thaliana ecotypes. Planta. 202, 387-396 (1997).

7. Magnani, E., Jiménez-Gómez, J. M., Soubigou-Taconnat, L., Lepiniec, L. \& Fiume, E. Profiling the onset of somatic embryogenesis in Arabidopsis. BMC Genomics. 18, 998 (2017).

8. Pathi, K. M., Tula, S. \& Tuteja, N. High frequency regeneration via direct somatic embryogenesis and efficient Agrobacteriummediated genetic transformation of tobacco. Plant Signal and Behav. 8, e24354 (2013).

9. Fei, L. \& Weathers, P. Bioreactors for plant embryogenesis and beyond. Methods in Molecular Biology 1359, 245-259 (2016).

10. Kim, Y. B., Reed, D. W. \& Covello, P. S. Production of triterpenoid sapogenins in hairy root cultures of Silene vulgaris. Nat Prod Commun. 10, 1919-1922 (2015).

11. Shasmita, Rai, M. K. \& Naik, S. K. Exploring plant tissue culture in Withania somnifera (L.) Dunal: in vitro propagation and secondary metabolite production. Crit Rev Biotechnol. 38, 836-850 (2017).

12. Meynet, J. Somatic Embryogenesis in Ranunculus asiaticus L. In: Bajaj, Y. P. S. (eds) Somatic embryogenesis and synthetic seed II. Biotechnology in agriculture and forestry, 31, Springer, Berlin, Heidelberg (1995).

13. Beruto, M. \& Debergh, P. Micropropagation of Ranunculus asiaticus: a review and perspectives. Plant Cell Tiss Org. 77, 221-230 (2004).

14. Xu, K. et al. Overexpression of RcLEC1-B, a HAP3 transcription factor of PLB from Rosa canina, increases the level of endogenous gibberellin and alters the development of cuticle and floral organs in Arabidopsis. Gene. 688, 119-131 (2019).

15. Jefferson, R. A., Kavanagh, T. A. \& Bevan, N. W. GUS fusions: $\beta$-glucuronidase as a sensitive and versatile gene fusion marker in higher plants. EMBO J. 6, 3901-3907 (1987)

16. Xu, K. et al. A lower $\mathrm{pH}$ value benefits regeneration of Trichosanthes kirilowii by somatic embryogenesis, involving rhizoid tubers (RTBs), a novel structure. Sci Rep-UK. 5, 8823 (2015).

17. Xu, K. et al. Regeneration of Solanum nigrum by somatic embryogenesis, involving frog egg-like body, a novel structure. PLoS One. 9, e98672 (2014).

18. Boutilier, K. et al. Ectopic expression of BABY BOOM triggers a conversion from vegetative to embryonic growth. Plant Cell. 14, 1737-1749 (2002).

19. Tian, C., Chen, Y., Zhao, X. \& Zhao, L. Plant regeneration through protocorm-like bodies induced from rhizoids using leaf explants of Rosa spp. Plant Cell Rep. 27, 823-831 (2008).

20. Zhou, X. et al. Desiccation treatment and endogenous IAA levels are key factors influencing high frequency somatic embryogenesis in Cunninghamia lanceolata (Lamb.) Hook. Front Plant Sci. 8, 2054 (2017).

21. Ikeda-Iwai, M., Umehara, M., Satoh, S. \& Kamada, H. Stress-induced somatic embryogenesis in vegetative tissues of Arabidopsis thaliana. Plant J. 34, 107-114 (2003).

22. Cheng, W. H. et al. Polyamine and its metabolite $\mathrm{H}_{2} \mathrm{O}_{2}$ play a key role in the conversion of embryogenic callus into somatic embryos in upland cotton (Gossypium hirsutum L.). Front Plant Sci. 6, 1063 (2015).

23. Barinova, I. et al. Regulation of developmental pathways in cultured microspores of tobacco and snapdragon by medium pH. Planta. 219, 141-146 (2004).

24. Touraev, A., Indrianto, A., Wratschko, I., Vicente, O. \& Heberle-Bors, E. Efficient microspore embryogenesis in wheat (Triticum aestivum L.) induced by starvation at high temperature. Sex plant reprod. 9, 209-215 (1996).

25. Raina, S. K. \& Irfan, S. T. High-frequency embryogenesis and plantlet regeneration from isolated microspores of indica rice. Plant Cell Rep. 17, 957-962 (1998).

26. Chiancone, B. \& Germanà, M. A. Microspore embryogenesis through anther culture in Citrus clementina Hort. ex Tan. Methods Mol Biol. 1359, 475-487 (2016).

27. Xu, K. et al. Rorippa indica regeneration via somatic embryogenesis involving frog egg-like bodies efficiently induced by the synergy of salt and drought stresses. Sci Rep-UK. 6, 19811 (2016). 
28. Patnaik, D., Mahalakshmi, A. \& Khurana, P. Effect of water stress and heavy metals on induction of somatic embryogenesis in wheat leaf base cultures. Indian J Exp Biol. 43, 740-745 (2005).

29. de Almeida, M., de Almeida, C. V., Mendes Graner, E., Ebling Brondani, G. \& Fiori de Abreu-Tarazi, M. Pre-procambial cells are niches for pluripotent and totipotent stem-like cells for organogenesis and somatic embryogenesis in the peach palm: a histological study. Plant Cell Rep. 31, 1495-1515 (2012).

\section{Acknowledgements}

This work was funded by the National Natural Science Foundation of China (No. 31872129 and 31902030), the Department of Science and Technology Planning Project of Henan Province (Nos. 192102110001 and 192102110124), the Training Program of Youth Backbone Teacher of Henan Province of 2017 (No. 2017GGJS146), Science and Technology Research Major Projects of Department of Education of Henan Province (No. 20A180034), and the School-based Project of Zhoukou Normal University (No. ZKNUB1201801).

\section{Author contributions}

K.X. conceived and designed the experiments. K.X., W.W., D.Y., X.L. and J.C. performed the experiments. K.X., X.L. and C.L. analyzed the data. B.F., Y.Z., M.C. and X.L. contributed reagents/materials/analysis tools. K.X. and C.L. wrote the manuscript. All authors have read and approved the manuscript.

\section{Competing interests}

The authors declare no competing interests.

\section{Additional information}

Correspondence and requests for materials should be addressed to C.-w.L.

Reprints and permissions information is available at www.nature.com/reprints.

Publisher's note Springer Nature remains neutral with regard to jurisdictional claims in published maps and institutional affiliations.

(c) (i) Open Access This article is licensed under a Creative Commons Attribution 4.0 International License, which permits use, sharing, adaptation, distribution and reproduction in any medium or format, as long as you give appropriate credit to the original author(s) and the source, provide a link to the Creative Commons license, and indicate if changes were made. The images or other third party material in this article are included in the article's Creative Commons license, unless indicated otherwise in a credit line to the material. If material is not included in the article's Creative Commons license and your intended use is not permitted by statutory regulation or exceeds the permitted use, you will need to obtain permission directly from the copyright holder. To view a copy of this license, visit http://creativecommons.org/licenses/by/4.0/.

(c) The Author(s) 2019 